\section{MICROSCOPICAL INVESTIGATIONS IN CHOLERA.}

Br HENRY OXLEY STEPHENS, Esq., M.R.C.S. \&c.

SURGEON TO ST. PETER'S HOSPITAL, BRISTOL, AND VICE-PRESIDENT OF THE BRISTOL MICROSCOPICAL SOCIETY.

ThE researches of Messis. Brittan and Swayne will doubt. less guide many more observers towards the same channels of investigation; and whatever may be the nature of the bodies so readily seen in the "rice-water" evacuations of cholera, this far is certain-the discoveries of those gentlemen are of the highest interest.

But the greatest cantion is needful in determining the nature of cryptogamic organisms developed in fluid media, even when the materials are in practised hands, and more especially so when these investigations are attempted, perhaps, for the first time.

It is well to know that mycetoid forms are so very generally and abundantly, and also rapidly, propagated in any fluids containing organic matters, and havo been exposed to the atmosphere, that mycologists lay little stress upon this circumstance. At this present time, mycology is but little studied without a small circle of botanists, and to most of the profession it is indeed an unknown land.

Were this not generally the case, toruloid filaments in organic fluids, and bacillarice in water, would not be regarded as unusual plienomena.

It is from this cause, when an investigator finds in certain fluids fungoid or algoid structures new to him, he naturally is tempted to conclude such to be novelties to science likewise. $\mathbf{I}$ am inclined to think $\mathrm{Mr}$. Grove has been led astray by this error. That gentleman considers the mucidinous filaments and germinating cells found in the urine of a cholera patient, as identical with the bodies of the "rice-water" evacuations, and which bodies I will venture to denominate Brittanian corpuscles.

The figures given by Mr. Grove, although good and distinct, cannot be admitted as demonstrating anything of the kind and the statement that they prove the vitality of the so-called cholera fungus by its germination, as far as published accounts go, is certainly not yet made manifest.

Many mont his since, - I think during the last winter, - my colleague, Dr. W. B. Herapath, gave me samples of albuminous urine, containing toluroid flaments in abundance, very like some of Mr. Grove's figures. I have seen similar in saccharine urine, and am strongly inclined to believe that all kinds of urine, healthy or otherwise, when decomposition has commenced will be found abounding with these mycelia. I have under examination, at this present time, a phial of "rice-water," which contains tufted septate mycelia in multitudes. The fluid is several weeks old, and is now horribly fotid.

Mr. Grove's experiment of transplanting his fungus into healthy urine, and the readiness with which it is propagated by this plan, seems clearly to indicate there is nothing specific, so far as cholera is concerned, in the nature of these organisms. No measurement is given, but from the figures alone the submersed form of some kind of mucor seems to be indicated; yet mucidinous filaments, propacated in fluids, are generally much larger in size than Mr. Grove's plants probably are; indeed, the aggregate of submersed mucor mycelia are usually visible to the nalked eye.

Figures 2 and 3 are evidently mycelian. Figure 4 seems to indicate an attempt towards the production of fructification. This last figure is indeed very like, as far as structure goes, the submersed state of mucor clavatus of Link, to which, if it were not for the probable difference of size, I should be inclined to refer Mr. Grove's plant.

Will that gentleman allow me to direct his attention to a highly interesting and important paper by the Rev. M. J. Berkeley, "On a Confervoid State of Mucor Clavatus Link," Annals of Natural History, vol. ii. October, 1837; he will there see how closely his own drawings, in outline, resemble those of $\mathrm{Mr}$. Berkeley.

I would suggest the following experiment:-A little flour paste should be moistened with a portion of urine containing these filaments, and placed under a glass. Possibly the aërial or normal state of the plant might be developed, and all doubts concerning the nature of it removed.

In the long and learned paper of Dr. Stuart Wilkinson, a case is detailed, in which mycoderms were produced abundantly within the uterine cavity, certainly an odd locality.

I think it probable these productions are a masked form of some penicillium or monilia, origin "ly inhabiting the dis- charges collected about the labia and orifice of the vagina; and then propagated upwards along the vagina and through the os uteri.

We here find the circumstances known as favourable to the growth of such fungi-viz., organic matters in a decomposing state, moisture and atmospheric air; for the flaccid vulva of an aged woman, in many positions of the body, will readily allow the ingress of air into the vagina.

These circumstances considered, the singularity of the habitat of Dr. Wilkinson's mould is not so inexplicable as at first sight it appears. I have myself seen spore-like cells, in the greatest abundance, in the fluid contents of an ovarian cyst. Nor are mycelia rare in the digestive and respiratory cavities of various animals. See "Des Vegetaux qui Croissent sur l'Homme et sur les Animaux Vivants. Par M. C. H. Robin," - a work which appears to ke little known to English medical men.

A word on Mr. Busk's assertion, that the Brittanian corpuscles are identical with the spores of an uredo. It is just but scarcely possible, Mr. Busk may have found the spores of tilletia caries in cholera evacuations, inasmuch as these are often abundant in common sorts of bread, and have mistaken these for the bodies described by Messrs. Brittan and Swoyne. The only fungus spores I am acquainted with, at all resembling the Brittanian bodies, are found in the hypogæous tribe, among the tuberacex.

Thus for was written several weeks since. In the interim, another paper by Mr. Grove has been published, with a reference to a paradoxical growth of a fungus within the yelk of an egg, detailed in the before-mentioned monggraph of Dr. Robin.

Even in this case, it is not absolutely necessary, in order to account for the introduction of the dactylimm oogenum, that we assume the productive matter of the fungus to liave entered the ovum through the general circulation of the fowl; but rather take this to be a case analogous to Dr. Wilkinson's, in which the plant passed through the apertures of the external organs. It is quite conceivable the spore of the dactylium might have been introduced into the cloaca of the bird, and during coitus carried through the oviducts, and then have gained entry into the ovum in its early state. There are difficulties of the same nature in the way in which entophybal fungi occur: doubtless all these apparent difficulties really consist in our imperfect knowledge and incomplete powers of investigation.

Bristol, December, 1849

ON SECTION OF THE TENDO-ACHILLIS AS A REMEDY FOR SPASM OF THE MUSCLES OF THE LEG.

\section{BY WILLTAM IFEMPSON DENHAN, Ese., Surgeon,} Hereford.

Facts in surgery and medicine are of two kinds. The first would illustrate occurrences exachly as they present themselves, the second would mould them to suit a theory. The first would be the beautiful delineations of an honest and observant mind, the sccond the ad captandum argument for personal advantage.

Surgery, like medicine, has much about it that is strictly empirical, not to say mechanical, with but a tinge of science. When we say "surgery," we but personify the subject, for we mean strictly some of its professors.

Muscles are excited to spasmodic contracion by the nervous power supplied to them, or they are not. If the former, the mechanical act of cutting through a tendon, to which the contracted muscles are inserted, is but a clumsy attempt to put a stop to a diseased action without interfering with the condition by which it was produced. If muscles be not excited to abnormal action by the power described, then must we unlearn all that we have bcen taught and seen, and Marshall Hall and his predecessors are but learned visionaries, whose eyes have been dimmed, and have seen nothing.

Those of my professional brethren who have seen practice in those districts where accidents are frequent and severe, must often have met with cases of fracture, and seen the usual accompaniment of violent spasm for the first night or two. But I will venture to assert, those surgeons, unless there have been something peculiarly severe and extraordinary in the nature of the accident, have not only cured the spasm without cutting through tendons, but have sent their patients abroad with more perfect and more immediately useful limbs than those who have so hastily resorted to section. 